\title{
Atendimento de reabilitação à pessoa idosa vítima de acidentes e violência em distintas regiões do Brasil
}

\author{
Rehabilitation service to the elder person \\ victim of accidents and violence on different regions of Brazil
}

Adalgisa Peixoto Ribeiro ${ }^{1}$

Elaine A parecida Chaves de Paiva Barter ${ }^{1}$

${ }^{1}$ Centro Latino-Americano deEstudos de Violência e Saúde Jorge Careli, Escola Nacional de SaúdePública Sergio Arouca, Fundação Oswaldo Cruz. Av. Brasil 4.036, Manguinhos. 21040-361 Rio deJaneiro RJ. adalpeixoto@yahoo.com.br
Abstract The purpose of this work is to describe the structure and characterize the services offered for rehabilitation of elder people, victims of accidents and violence, based on the main public policies of health for this population in Brazil. Following the principles of the triangulation method, a 27 question questionnaire was applied to 19 rehabilitation services (five in $M$ anaus, seven in Recife, two in Braślia, two in Rio de Janeiro and three in Curitiba) about structure and organization of the service besides data registration. $M$ anagers and health professionals were interviewed about the flow, characterization and specificities of the service to elder people, protection chains, services evaluation and suggestions. Services in Manaus and Brasília are better prepared to attend elder victims of accidents and violence. The services in Brasília surpass the specific issues of elderly care. The rehabilitation units in Recife are more unprepared, especially regarding laboratorial support, qualification of professionals to identify and attend the cases of violence, registration and analysis of data. It is concluded that the rehabilitation service presents great fragility on the implantation of public policies and in insertion of the violence theme.

Key words Health of the elderly, Public policy, Violence against the elderly
Resumo Objetiva-se descrever a estrutura e caracterizar 0 atendimento prestado por serviços de reabilitação que atendem idosos vítimas de acidentes e violência, baseando-se nas principais políticas públicas de saúde di rigidas à população idosa no país. Seguindo os princípios da triangulação de métodos, aplicou-se um questionário a 19 serviços de reabilitação (cinco em M anaus, sete em Recife, dois em Brasília, dois no Rio de Janeiro e três em Curitiba) composto por 27 questões referentes à estrutura e organização do serviço e registro dos dados. Foram entrevistados gestores e profissionais sobre fluxo, caracterização e especificidades do atendimento ao idoso, redes de proteção, avaliação dos serviços e sugestões. Os serviços de M anause Braślia estão maisbem preparados para atender aos idosos vítimas de acidentes e violência. Os de Brasília sobressaem nas questões mais específicas ao atendimento do idoso. As unidades dereabilitação de Recifeapresentam-semenos pre paradas, especialmente nos itens de suporte laboratorial, capacitação de profissionais para identificar e atender os casos de idosos em situação de violência, registro e análise dos dados. Conclui-se que 0 atendimento de reabilitação apresenta grandes fragilidades na implantação das políticas públicas e na inserção do tema da violência.

Palavras-chave Saúde do idoso, Políticas públicas, Violência contra o idoso 
Introdução

O objetivo deste artigo é descrever a estrutura e caracterizar 0 atendimento prestado por serviços de reabilitação que atendem pessoas idosas vítimas de acidentes eviolências, baseando-senas diretrizes das principais políticas públicas desaúde dirigidas à população idosa no país.

A saúde do idoso resulta da interação entre as condições físicas e mentais, a independência na vida diária, a integração social, o suporte familiar e até mesmo a independência econômica. O bem-estar na velhice, ou saúde num sentido amplo, seria o equilíbrio entreas diversas dimensões da capacidadefuncional do idoso, sem, contudo, significar ausência de problemas ${ }^{1,2}$.

A capacidadefuncional do idoso édeterminada einfluenciada por fatores demográficos, socioeconômicos, culturais, psicológicos, doenças ealterações fisiológicas do envelhecimento que vão caracterizar o comportamento e o estilo de vida.

Osacidentes eviolências representam importante impacto na capacidade funcional dos idosos brasileiros. Os registros disponibilizados pelo Departamento de Informática do Sistema Ú nico de Saúde (Datasus) evidenciam que em 2008 foram 122.065 internações de idosos por causas externas; entre elas, $49,5 \%$ se referem a quedas, $7,2 \%$ a acidentes de transporte e $11,5 \%$ a causas externas não classificadas. As internações por agressão representaram nesse mesmo ano 1,6\% dessas hospitalizações ${ }^{3}$. É importante destacar que muitos eventos violentos não exigem internação e por isso são considerados menos graves, mas envolvem agressões físicas, psicológicas e negligências a que os idosos estão expostos no contexto familiar, na comunidade e nas instituições e não são notificadas. Por esse motivo, não se pode ter a exata noção das vivências deviolência dos idosos brasileiros.

A Política Nacional de Redução da Morbimortalidade por Acidentes e Violências (PNR$M A V$ ) preconiza que a reabilitação de sequelas advindas de acidentes eviolências devefavorecer 0 alcance da independência do paciente dentro da nova situação 4 .

A reabilitação é um processo global e dinâmico com o objetivo de recuperar a saúdefísica e psicológica da pessoa portadora de deficiência ou com funções prejudicadas por doença ou evento traumático. Está associada a um conceito mais amplo de saúde, incorporando o bem-estar físico, psíquico e social, tendo como meta final a reintegração social do paciente. No caso dos idosos, especificamente, visa à restauração das ha- bilidades funcionais, aumentando sua capacidade residual ${ }^{5}$. A reabilitação é necessária quando se trata de doenças crônicas, sequelas neurológicas e lesões traumáticas e deve ser realizada com equipe multiprofissional 6 .

0 processo de reabilitação segue al guns passos naturais no cuidado à saúde, tendo suas especificidades de acordo com a clientela. Primeiramente, é realizado o diagnóstico da patologia, deficiência ou incapacidade existente, definido e avaliado o prognóstico e o potencial de reabilitação do paciente. A partir de então fazem-se 0 planejamento e a prescrição do tratamento. Algumas metas são comuns nesse processo: prevenção do descondicionamento físico e psicológico, das sequelas decorrentes do imobilismo e isolamento próprios da lesão; facilitação dos processos de recuperação e regeneração natural; estímulo, maximização e compensação das capacidades residuais e, se possível, promoção da integração socioprofissional.

Para o paciente idoso, muitos são os desafios na realização desse atendimento; dentreeles, manter a capacidade funcional e evitar a institucionalização. Os idosos têm necessidades especiais que exigem que o profissional, além da doença existente, considere as mudanças fisiológicas do envelhecimento no planejamento, no desenvolvimento e na implementação da terapêutica ${ }^{7,8}$.

\section{M etodologia}

A pesquisa se pautou na triangulação demétodos integrando as abordagens quantitativas e qualitativas, ampliando o espectro de contribuições teórico-metodológicas, de forma a perceber movimentos, estruturas, ação dos sujeitos, indicadores e relações entre micro e macrorrealidades 9 .

Os parâmetros norteadores para a análise da estrutura e das ações de saúde foram definidos tomando-se como base as principais políticas de atendimento integral à vítima de acidente e violência e ao idoso: (1) Política Nacional de Redução da M orbimortalidade por Acidentes e Violências"; (2) Estatuto do Idoso, que reforça as diretrizes da Política Nacional do Idoso e versa sobre os direitos fundamentais e as necessidades deproteção ${ }^{10}$; e(3) Política Nacional de Saúdedo Idoso $0^{6,11}$.

A seleção das cidades onde se realizou a pesquisa (M anaus, Recife, Brasília, Rio de Janeiro e Curitiba) se deu pelo fato de elas apresentarem elevadosíndices demorbimortalidade por violência, segundo Souza eVeiga ${ }^{12}$. Com exceção do Rio 
de Janeiro, as demais cidades foram as primeiras colocadas em suas respectivas regiões em termos de mortalidade por causas externas. O Rio de Janeiro foi escolhido devido a sua complexidade.

$\mathrm{Na}$ abordagem quantitativa, foi usado um questionário para identificar a estrutura e qualificar 0 atendimento e as ações oferecidas. Foi preenchido em nível local por 19 serviços de reabilitação (cinco em $M$ anaus, sete em Recife, dois em Braślia, dois no Rio de Janeiro etrês em Curitiba) e apresentou 27 questões divididas em quatro blocos referentes a identificação, estrutura e organização do serviço e registro dos dados.

Para o processamento dessas informações coletadas foi criado um banco de dados, no programa CSPro versão 3.2. A pós as correções e críticas, os bancos foram convertidos para o software SPSS versão 13.0, no qual foi realizada a descrição de frequências.

Um conjunto deindicadoresfoi construído para se ter um diagnóstico dos sistemas locais de reabilitação para atender idosos vítimas de acidentes e violência. A princípio foram incorporados alguns desses dispositivos criados para a pesquisa Análise Diagnóstica deSistemas Locais deSaúdepara Atender aos Agravos Provocados por Acidentes e Violências ${ }^{13}$. Na presente pesquisa investiu-sena criação de novos indicadores específicos às questões do idoso, baseando-se nas diretrizes das políticas anteriormente citadas. Para essa construção dos indicadores avaliativos usou-se a Técnica Grupo Nominal, que consiste em atribuir um escore aos indicadores visando consolidar o consen $\mathrm{SO}^{14,15}$. Sinteticamente, esse processo consistiu nas seguintes etapas: elaboração deuma lista deindicadores aplicados aos dados coletados nas unidades de reabilitação dos cinco municípios; exclusão dos que se mostraram pouco discriminadores eflexibilização dos critérios de constituição dos que permaneceram; submissão da lista dos indicadores aos espe cialistas locais, com debate sobre a avaliação dessesindicadores, para legitimar os consideradosimportantes e excluir os demais; análise das respostas finais dos especialistas; construção de índices sintéticos compostos por mais de um indicador; e aplicação final dos indicadores.

$\mathrm{Na}$ abordagem qualitativa foram feitas entrevistas semiestruturadas com nove questões sobre descrição do fluxo, caracterização e especificidades do atendimento ao idoso; família e re des de proteção; avaliação dos serviços e sugestões, aplicadas aos coordenadores das unidades efisioterapeutas.

As entrevistas foram transcritas e processadas formando um banco onde ficaram agrupadas de acordo com as cidades, os sujeitos entre vistados e o bloco de temas. As análises seguiram os princípios da Análise de Conteúdo, modalidade temática adaptada da proposta de Bardin ${ }^{16}$, e foram conduzidas basicamente por um recorte interpretativo ${ }^{17}$.

0 questionário e as entrevistas foram submetidos aos pesquisadores responsáveis pelo trabalho no município eanalisados criticamentepor especialistas na área do atendimento e do tema da violência. A coleta de dados aconteceu entre os meses de agosto de 2007 e março de 2008. A pesquisa obteve aprovação do Comitê de Ética em Pesquisa da Escola Nacional de Saúde Pública Sergio Arouca, da Fundação Oswaldo Cruz, e das Secretarias de Saúde dos municípios.

\section{Resultados ediscussão}

Entre as 19 unidades de reabilitação estudadas nas cinco capitais, $42,1 \%$ são serviços de referência, outros $42,1 \%$ são unidades de primeiro nível e $15,8 \%$ de nível intermediário. No universo de unidades pesquisadas, $47,4 \%$ estão vinculadas ao governo municipal, $31,6 \%$ ao governo estadual, $10,5 \%$ ao federal e $10,5 \%$ conveniadas com o SUS $(10,5 \%)$.

Caracterização da estrutura existente no atendimento de reabilitação

As unidades de Brasília não informaram o número de leitos e vagas disponíveis para atendimento de reabilitação. Nas outras cidades, a mé dia do número deleitos disponíveis, por unidade, foi de três em Recife, 30,6 em M anaus e 322,5 em Curitiba. A penas uma unidade do Rio de Janeiro informou esta questão; a média se confunde com o número total de leitos e vagas: vinte.

Nas cinco cidades, a informação sobre o número de idosos atendidos com sequelas de eventos acidentais ou violentos ficou muito prejudicada, o que sugere a inserção ai nda incipiente do tema violência nos serviços de saúde, especialmentena reabilitação. A identificação da violência que levou o usuário a um serviço de saúde muitas vezes requer capacitação, treinamento e sensibilidade para perceber situações em que esses eventos estão camuflados nas histórias que vêm à tona durante a anamnese. Também é fato que a invisibilidade desses eventos se concretiza em seu baixo registro nos prontuários, apesar de sua alta magnitude e prevalência ${ }^{18}$.

Em 2006, foram realizados 2.029 .889 atendimentos de reabilitação nas cinco cidades (duas unidades de Recifenão informaram); entreestes, 
$29,3 \%$ foram de pacientes idosos. No entanto, esse percentual pode ser maior, pois um serviço de Braślia, dois de $M$ anaus e cinco de Recifenão informaram o número de atendimentos de idosos. Q uando se investigou o número de idosos atendidos por causas externas, somente uma unidade do Rio de aneiro informou ter recebido cinco idosos por causa de acidentes.

As unidades de $M$ anaus surpreendem em re lação aos recursos tecnológicos para exames complementares, pois grande parte dispõe dos recursos básicos como análise clínica laboratorial, radiologia convencional e ultrassonografia. Poucas unidades informaram ter os equi pamentos para medicina nuclear, urodinâmica eaudiometria (Tabela 1).

Dos 19 serviços pesquisados, seis informaram dispor de transporte para pacientes (dois em Manaus e em Recife), suporte para laboratório de radiologia (dois serviços em M anaus e no Rio de Janeiro eum em RecifeeBraślia) ecinco indicaram ter suporte para patologia clínica (um em cada cidade), como prevêa PortariaM S/GM n 818. Grande parte das unidades sinalizou que esses recursos são possíveis graças à articulação com a rede.

$\mathrm{Na}$ entrevista, gestores e profissionais falaram da estrutura dos serviços. Um gestor de $M$ anaus avaliou que sua unidade tem ambiente adaptado às necessidades do idoso: Tudo aqui é dimensionado para cadeirantes, para idosos; os banhei rostêm barra desegurança, a gentetem pessoas específicas, estrutura específica, que colabora muito com isso.

Apesar dessas adaptações estruturais, a dificuldade de locomoção, a falta de transporte e as alterações físico-funcionais dos idosos tornamse obstáculos no acesso ao serviço: Às vezes, eles pegam dois, três ônibus; quando chegam aqui já estão cansados, com pressão alta, e aí dificulta o tratamento. Uma alternativa foi a parceria com a Prefeitura de $M$ anaus para fornecer ônibus aos que apresentam dificuldades de locomoção, mas os carros têm rotas específicas e os pacientes precisam dar sorte demorar perto daquela rota ondeo ônibus passa. Em Recife, um gestor afirma que as instalações da sua unidade não são adequadas para receber idosos. Para ele, essa é uma questão a ser discutida nas políticas públicas para idosose deficientes.

Os serviços dereabilitação apresentaram seus quadros de profissionais (Tabela 2). Curitiba tem unidades que possuem maior número de profissionais nas diversas categorias. Já Brasília tem unidades com menos assistentes sociais, enfermeiros, fonoaudiólogos, psicólogos, nutricionistas e farmacêuticos. Profissionais importantes para o trabal ho de reabilitação física como fisioterapeuta enutricionista estão em número reduzido no Rio de Janeiro.

Seguindo o Estatuto do I doso, a reabilitação deve ser orientada pela geriatria e gerontologia. Entre os serviços investigados, dispõem de profissionais com capacitação em gerontologia uma unidade de M anaus (um médico e um psicólogo); duas de Recife (um assistente social, um médico e dois fisioterapeutas); uma no Rio de Janeiro (um psicólogo e um enfermeiro). Uma unidade de Curitiba tem três desses técnicos e a Brasília possui gerontólogos, mas nas duas cidades não foram informadas as categorias.

As duas unidades de Brasília, uma de Curitiba, duas de M anaus e duas de Recife informaram ter protocolos para 0 atendimento de idosos em situação de acidentes e violência. No Rio de Janeiro nenhuma unidade dispõe de tal protocolo, que é preconizado pela PNRM AV para padronizar as condutas, racionalizar 0 atendimento e reduzir custos.

Tabela 1. Distribuição das unidades de reabilitação segundo recursos tecnológicos.

\begin{tabular}{|c|c|c|c|c|c|c|c|}
\hline \multirow[t]{2}{*}{ Recursos } & \multicolumn{2}{|c|}{$\mathrm{M}$ anaus $(\mathrm{N}=5)$} & \multirow{2}{*}{$\frac{\text { Recife }(N=7)}{N}$} & \multirow{2}{*}{$\frac{\text { Brasília }(\mathrm{N}=2)}{\mathrm{N}}$} & \multicolumn{2}{|c|}{ Rio de Janeiro $(\mathrm{N}=2)$} & \multirow{2}{*}{$\frac{\text { Curitiba }(\mathrm{N}=3)}{\mathrm{N}}$} \\
\hline & $\mathrm{N}$ & S/inf & & & $\mathrm{N}$ & S/inf & \\
\hline Análise clínica laboratorial & 5 & - & 2 & 1 & 1 & 1 & 1 \\
\hline M edicina nuclear & 1 & 1 & 0 & 0 & 0 & 1 & 1 \\
\hline Radiologia convencional & 4 & - & 1 & 1 & 2 & - & 0 \\
\hline Urodinâmica & 1 & - & 0 & 1 & 0 & 1 & 1 \\
\hline UItrassonografia & 3 & - & 1 & 1 & 0 & 1 & 1 \\
\hline Audiometria & 0 & - & 1 & 1 & 0 & 1 & 1 \\
\hline
\end{tabular}

-: sem registro para o item; 0: unidadeinformou quenão possui. 
Tabela 2. Número de profissionais disponíveis para atendimento de reabilitação segundo a cidade.

\begin{tabular}{|c|c|c|c|c|c|c|c|c|c|c|}
\hline \multirow[t]{2}{*}{ Profissionais } & \multicolumn{2}{|c|}{ Manaus $(\mathrm{N}=5)$} & \multicolumn{2}{|c|}{ Recife $(\mathrm{N}=7)$} & \multicolumn{2}{|c|}{ Brasília $(\mathrm{N}=2)$} & \multicolumn{2}{|c|}{ Rio de Janeiro $(\mathrm{N}=2)$} & \multicolumn{2}{|c|}{ Curitiba $(\mathrm{N}=3)$} \\
\hline & $\mathrm{N}$ & S/inf & $\mathrm{N}$ & S/inf & $\mathrm{N}$ & S/inf & $\mathrm{N}$ & S/inf & $\mathrm{N}$ & S/inf \\
\hline M édico fisiatra & 0 & - & 1 & 1 & 2 & 1 & 6 & - & 395 & - \\
\hline M édico psiquiatra & 5 & - & 7 & 1 & 1 & - & - & - & 1 & 1 \\
\hline $\begin{array}{l}\text { M édico com formação } \\
\text { em saúde mental }\end{array}$ & 4 & - & 0 & 1 & 0 & 1 & - & - & 1 & 1 \\
\hline Fonoaudiólogo & 9 & - & 15 & - & 2 & - & 8 & - & 5 & - \\
\hline Enfermeira & 31 & 1 & 5 & 1 & 0 & 1 & 17 & - & 231 & - \\
\hline Assistente social & 22 & - & 4 & 1 & 1 & 1 & 3 & - & 44 & - \\
\hline Psicólogo & 11 & 1 & 8 & 1 & 2 & 1 & 5 & - & 24 & - \\
\hline Nutricionista & 4 & 1 & 3 & 1 & 2 & 1 & 2 & - & 18 & - \\
\hline Fisioterapeuta & 35 & 1 & 58 & - & 16 & - & 6 & 1 & 38 & - \\
\hline Terapeuta ocupacional & 0 & - & 7 & - & 2 & - & 2 & 1 & 10 & - \\
\hline Farmacêutico & 11 & 1 & 5 & 1 & 3 & 1 & 4 & - & 88 & - \\
\hline Responsável técnico & 3 & 1 & 3 & 1 & 2 & - & 2 & - & 211 & - \\
\hline $\begin{array}{l}\text { Técnico/auxiliar de } \\
\text { enfermagem }\end{array}$ & 113 & 1 & 129 & 1 & 71 & 1 & 10 & 1 & 1.029 & - \\
\hline $\begin{array}{l}\text { Técnico com experiência ou } \\
\text { capacitação em reabilitação }\end{array}$ & 3 & 1 & 1 & 1 & - & 2 & 0 & 1 & 1 & 2 \\
\hline
\end{tabular}

-: sem registro para o item; 0: unidadeinformou quenão possui.

Caracterização do atendimento de reabilitação

0 fluxo do atendimento de reabilitação foi apresentado deforma fragmentada esem diferenciações para idosos vítimas de acidentes e violências, segundo gestores e profissionais entrevistados. De forma geral, o paciente vem encaminhado por outro serviço desaúde ou por uma central de regulação e é agendado pela rede própria municipal ou conveniada. $\mathrm{Na}$ unidade de reabilitação, passa por uma triagem com fisioterapeuta, terapeuta ocupacional, psicólogo, fonoaudiólogo e assistente social; recebe tratamento adequado e retorna ao profissional que o encaminhou.

As unidades de cada cidade têm características específicas. M anausapresenta grande demanda de pacientes, mas a espera pelo atendimento dura em média uma semana. Existe uma rotativa onde os pacientes pegam o cartãozinho da marcação de consultas, ficam na lista de espera, avisam a gente da gravidade do problema e, quando vai surgindo vaga, aí se liga para a casa deles chamando. Apesar da generalização no atendimento dos pacientes, o profissional coloca uma observação queévítima deacidente, queéidoso, ea gentejá dá uma prioridade. Temos fisioterapeuta específico para atender idosos.
Em Recife, há dificuldade em acolher vítimas de agressões intrafamiliares e de quedas nas vias públicas. Para o gestor, a Secretaria M unicipal de Saúde quer priorizar pacientes idosos e com deficiência, mas dá a entender que isso ainda não é realidade.

Profissionais de Brasília consideram pequeno o fluxo de idosos em situação de violência, o que associam à dificuldade em identificar os casos, resultando na desvalorização da fala dos pacientes. Isso parece refletir despreparo dosprofissionais em lidar com as consequências da violência. Esse despreparo já foi evidenciado por alguns autores que indicam as lacunas ainda existentes na capacitação profissional sobreo tema ${ }^{19}$.

Técnicos do Rio de Janeiro afirmaram que a maioria dos idosos que procura atendimento 0 faz devido a sequelas funcionais. Esses profissionais se mostraram preocupados com a insuficiência de serviços de reabilitação, o que muitas vezes leva a uma descontinuidade nos tratamentos. Talvez por isso a falta de acesso e a baixa cobertura sejam uma realidade local.

Em Curitiba os pacientes são atendidos por ordem de chegada, mas a espera é de até dois meses. Os profissionais destacam que são poucos os serviços credenciados ao SUS; creem que têm dado vazão à demanda e que os idosos fi- 
cam satisfeitos com os resultados. Para eles, faltam centros que ofereçam uma reabilitação específica. Uma estratégia apontada é o encaminhamento para as universidades que prestam serviço de excelência.

Entre as ações e os atendimentos oferecidos pelas unidades de reabilitação, a aval iação médica, clínica e funcional, 0 atendimento e a avaliação fisioterapêutica fazem parte do cotidiano da maioria desses serviços (Tabela 3 ).

A reinserção social éuma diretriz preconizada nas principais políticas dirigidas ao idoso e também um dos objetivos da reabilitação. É curioso notar que em Brasília eCuritiba as unidades informaram não desenvolver atividades com esse fim.

0 fornecimento de órteses é realizado por duas unidades de $M$ anaus e do Rio de Janeiro e uma de Curitiba; as próteses são dispensadas por dois serviços de Manaus e um de Curitiba. Os meios auxiliares para locomoção estão mais disponíveis: em duas unidades de reabilitação de
M anause uma em Recife, no Rio deJ aneiro eem Curitiba (Tabela 4). A provisão desses recursos é preconizada pela PN RM AV para favorecer a independência do paciente4.

Comparando esses dados com os observados por M inayo e Deslandes ${ }^{13}$ para a população geral nas mesmas capitais, em M anaus as informações se confirmam em relação aos idosos. Em Recife, surpreende que nenhuma das sete unidades ofereça órteses e próteses, pois na pesquisa anterior, duas das seis que participaram as ofereciam.

Os gestores tenderam a dizer quea idade não interfere no atendimento, e sim a gravidade do caso que levou a pessoa ao serviço. M as grande parte dos fisioterapeutas afirmou que existe essa discriminação, que os encaminhamentos externos são muito dificultosos, implicando idas evindas do pacienteentreos serviços, além do declínio da funcionalidade pelo atraso no atendimento. Outros, concordando com os gestores, disseram que a idade não interfere na recepção do idoso.

Tabela 3. Distribuição das unidades de reabilitação segundo as atividades realizadas.

\begin{tabular}{|c|c|c|c|c|c|}
\hline Atividade & $\begin{array}{l}\text { Manaus } \\
\frac{(\mathrm{N}=5)}{\mathrm{N}}\end{array}$ & $\begin{array}{l}\text { Recife } \\
(\mathrm{N}=7) \\
N\end{array}$ & $\begin{array}{c}\begin{array}{c}\text { Brasília } \\
(\mathrm{N}=2)\end{array} \\
\frac{N}{N}\end{array}$ & $\begin{array}{c}\text { Rio de Janeiro } \\
(\mathrm{N}=2)\end{array}$ & $\begin{array}{l}\text { Curitiba } \\
\frac{(\mathrm{N}=3)}{\mathrm{N}}\end{array}$ \\
\hline Atendimento em grupo & 4 & 2 & 2 & 1 & 2 \\
\hline Prevenção de sequelas e incapacidades secundárias & 4 & 5 & 2 & 1 & 2 \\
\hline Estimulação neuropsicomotora & 5 & 4 & 1 & 1 & 2 \\
\hline Atendimento/orientação familiar & 4 & 3 & 2 & 1 & 3 \\
\hline Avaliação médica, clínica e funcional & 5 & 5 & 2 & 1 & 3 \\
\hline Avaliação clínica geriátrica & 2 & 1 & 2 & - & 2 \\
\hline Avaliação clínica gerontológica & 1 & 2 & 2 & - & 2 \\
\hline Avaliação e atendimento em fisioterapia & 4 & 7 & 1 & 1 & 3 \\
\hline Avaliação e atendimento em terapia ocupacional & 1 & 2 & 1 & 1 & 2 \\
\hline Avaliação e atendimento em fonoaudiologia & 1 & 5 & 2 & 1 & 2 \\
\hline Avaliação e atendimento em psicologia & 4 & 2 & 2 & 1 & 2 \\
\hline Avaliação e atendimento em serviço social & 5 & 3 & 1 & 1 & 2 \\
\hline Avaliação e atendimento em enfermagem & 4 & 1 & 1 & 1 & 2 \\
\hline Avaliação e atendimento em nutrição & 3 & 1 & 1 & 1 & 2 \\
\hline Atendimento medicamentoso com dispensação de remédios & 3 & 4 & 0 & 1 & 1 \\
\hline $\begin{array}{l}\text { Avaliação funcional e diagnóstico de eletroneuromiografia e } \\
\text { potenciais evocados }\end{array}$ & 0 & 0 & 0 & 1 & 2 \\
\hline Atendimento clínico nas diversas especialidades médicas & 3 & 2 & 0 & 1 & 1 \\
\hline Atividades de reinserção na vida comunitária & 2 & 2 & 0 & 1 & 0 \\
\hline Ações de promoção do autocuidado & 5 & 3 & 1 & 1 & 2 \\
\hline $\begin{array}{l}\text { Ações de fomento da rede de solidariedade para idosos frágeis } \\
\text { e sua família }\end{array}$ & 1 & 3 & 1 & - & 1 \\
\hline $\begin{array}{l}\text { Ações de estímulo à participação em grupos de terceira idade, } \\
\text { consel hos comunitários etc. }\end{array}$ & 3 & 5 & 2 & 1 & 2 \\
\hline
\end{tabular}


Tabela 4. Distribuição das unidades de reabilitação segundo ações envolvendo órteses, próteses e meios auxiliares de locomoção.

\begin{tabular}{|c|c|c|c|c|c|c|c|c|}
\hline \multirow[b]{2}{*}{ A ção } & \multicolumn{2}{|c|}{ Manaus $(\mathrm{N}=5)$} & \multirow{2}{*}{$\frac{\text { Recife }(N=7)}{N}$} & \multirow{2}{*}{$\frac{\text { Brasília }(\mathrm{N}=2)}{\mathrm{N}}$} & \multicolumn{2}{|c|}{ Rio de Janeiro $(\mathrm{N}=2)$} & \multicolumn{2}{|c|}{ Curitiba $(\mathrm{N}=3)$} \\
\hline & $\mathrm{N}$ & S/inf & & & $\mathrm{N}$ & S/inf & $\mathrm{N}$ & S/inf \\
\hline \multicolumn{9}{|l|}{ Órteses } \\
\hline Avalia indicação & 5 & - & 5 & 2 & 2 & 1 & 2 & 1 \\
\hline Prescreve & 4 & - & 4 & 2 & 2 & 1 & 2 & 1 \\
\hline Treina o uso & 4 & - & 2 & 2 & 2 & 1 & 2 & 1 \\
\hline Acompanhamento & 4 & - & 3 & 2 & 2 & 1 & 1 & 1 \\
\hline \multicolumn{9}{|l|}{ Próteses } \\
\hline Avalia indicação & 2 & 1 & 3 & 2 & 1 & 1 & 2 & 1 \\
\hline Prescreve & 1 & 1 & 1 & 2 & 1 & 1 & 2 & 1 \\
\hline Treina o uso & 3 & 1 & 0 & 2 & 2 & 1 & 2 & 1 \\
\hline Acompanhamento & 3 & & 1 & 2 & 2 & 1 & 1 & 1 \\
\hline \multicolumn{9}{|l|}{ M eios auxiliares } \\
\hline Avalia indicação & 5 & - & 4 & 2 & 2 & 1 & 2 & 1 \\
\hline Prescreve & 5 & - & 3 & 2 & 2 & 1 & 2 & 1 \\
\hline Treina o uso & 5 & - & 2 & 2 & 2 & 1 & 1 & 1 \\
\hline Acompanhamento & 5 & - & 3 & 2 & 2 & 1 & 1 & 1 \\
\hline
\end{tabular}

Gestores e profissionais reconhecem que 0 idoso requer mais atenção e tratamento diferenciado devido às suas especificidades. Na visão de um gestor, é necessário ter mais envolvimento, humanização e compreensão com a temática [violência] e com os próprios idosos. Ele terminou dizendo que poucos estão preparados para cuidar de idosos; os profissionais precisam se capacitar mais.

Um gestor de Recife apontou como problema a alta desses pacientes, que se sentem acolhidos e não querem deixar o serviço, mesmo com o fim do tratamento. A isso denominou cronicidade da rede de reabilitação. Para os técnicos, os idosos permanecem por mais tempo no serviço de reabilitação, pois são sedentários e não têm, externamente, nenhuma atividade física; eles se limitam a realizar só a fisi oterapia, que não ésuficiente. Essa é uma forma mais técnica de visualizar essa questão. Diogo ${ }^{20}$ traz o lado mais humanizado dos vínculos que se estabelecem no atendimento, por parte tanto do profissional como do idoso. Discute que é comum existir a dificuldade dos profissionais em determinar com precisão quando o idoso estará "pronto" para a alta. Destaca o sentimento de protecionismo que a equipe apresenta nesses casos. Por isso mesmo, é necessária a realização de uma avaliação domiciliar para orientação de familiares e cuidadores, preparando-os para a alta do paciente, pois a realidade do idoso em seu ambiente domiciliar e social pode exigir adaptações.
Outra questão importante é a relutância do idoso à alta ${ }^{20} .0$ medo da solidão após longo período de convivência com os profissionais e 0 companheirismo conquistado entre os outros pacientes no local da reabilitação pode estar associado a essa recusa. A equipe precisa ter sensibilidade para perceber tais questões, demonstrar apoio e disponibilidade para atender esses idosos e incentivá-los à troca de experiências em grupo.

A preparação para a alta é uma atividade presente em grande parte das unidades deste estudo, exceto em Brasília, ondenenhuma delas atenta para a questão. Uma unidade de Curitiba tem uma conduta específica de alta supervisionada para idoso com sequelas neurológicas, onde 0 paciente retorna periodicamente para 0 acompanhamento.

Técnicos do Rio de aneiro ede Curitibaindicaram que os idosos tendem a colaborar com o tratamento, sendo participativos, cumprindo horários e seguindo as prescrições. M as a dificuldade maior está relacionada às questões sociais e financeiras dos idosos em arcar com o transporte, por isso faltam às sessões e até abandonam o tratamento. Foi relatada a falta de apoio da família, instituição importante no processo de cuidado ao paciente idoso.

$\mathrm{Na}$ entrevista, os técnicos disseram que na atenção à saúde do idoso o apoio informal e familiar é fundamental para o sucesso da terapêutica. Isso não significa que o Estado transfira seu 
papel de promoção, proteção e recuperação da saúde para a família; ao contrário, deve-se otimizar o suporte familiar ${ }^{1}$.

Para um gestor de Curitiba, se não houver a participação da família fica muito difícil reabilitar. Um fisioterapeuta indicou que a negligência familiar acontece em muitos casos atendidos na unidade.

N a reabilitação a terapêuticanão pode ser finalizada em sessões presenciais, devendo ser um processo contínuo, reforçado pelos familiares e cuidadores no domicílio. Alguns gestores afirmaram que a interação da equipe com a família acontece em todos os atendimentos, desde a fase inicial. Técnicos relataram que essa interação se dá por meio de orientação escrita, cartilhas, palestras, reuniões e festas comemorativas, por exemplo.

Um gestor destacou que no seu serviço a participação da famíliaéobrigatória; outro disseque o interesse que esse idoso, vítima de acidente e violência, tenha um melhor acompanhamento parte da própria família. Além do papel operacional de levar o idoso ao serviço, a família provê cuidados, dá apoio psicológico e estímulo para que as práticas reabilitadoras sejam continuadas.

$\mathrm{Na}$ percepção de um técnico, os familiares buscam uma redução de responsabilidades sem 0 interesse de participar do tratamento. Se por um lado a família tenta diminuir sua responsabilidade no cuidado, por outro, na maioria das vezes, ela não tem preparo, conhecimento e recursos domiciliares essenciais para o cuidado e seguimento das orientações terapêuticas. Também é frequente o familiar cuidador não ter boa relação afetiva com o idoso.

A forma de a família lidar com o idoso é influenciada pelo modo como os vínculos afetivos foram construídos ao longo da vida. Estudos ${ }^{21,22}$ mostram que laços frouxos ou marcados por experiências de violência tendem a se perpetuar e prevalecer nas relações durante a velhice.

Fisioterapeutas revelam tendência em não abordar questões de violência; no caso de idosos com transtornos mentais, a conduta é passar as informações para a família. Alguns se esquivaram de responder sobre 0 atendimento dos casos de violência, justificando que nunca os receberam. Talvez não tenham capacitação ou sensibilidade para identificar os casos que surgiram na reabilitação e se baseiam na experiência e no bom senso para esse cuidado.

Apenas duas unidades de $M$ anaus, uma do Rio de Janeiro e uma de Curitiba informaram que realizam atendimento domiciliar, que na reabilitação visam reintegrar o paciente em seu núcleo familiar e de apoio, proporcionar assistência humanizada e integral. Um serviço de $M$ anaus informou ter equipe multidisciplinar para a reabilitação domiciliar de idosos, vítimas de acidentes e violências. Embora recomendada pelas políticas, a aproximação dos serviços com a família parece não ser uma rotina e só ocorre em casos excepcionais. Um gestor enfatizou que as visitas domiciliares só ocorrem quando há uma dificuldade muito grande, quando o paciente começa a faltar.

Além de capacitação, as equipes de saúdeque atendem vítimas de acidentes e violência precisam de apoio emocional para aliviar as angústias e também de suporte institucional para o fortalecimento de diálogos e mecanismos de humanização do atendimento ${ }^{23}$. 0 suporte e 0 acompanhamento às equipes existem em um serviço de M anaus, um de Recife e um de Curitiba.

A integração com as equipes do Programa de Saúde da Família para a manutenção da capacidade funcional do idoso é mantida por uma unidade de Recifee uma deCuritiba; nas outras cidades, nenhum serviço mantém esse vínculo preconizado pela Política Nacional de Saúde do Idoso.

$\mathrm{Na}$ atenção ao idoso, a abordagem preventiva e a intervenção precoce são sempre preferíveis às intervenções curativas tardias ${ }^{11}$. Para que isso aconteça, é preciso que a equipe de saúde tenha vigilância constante com aplicação de instrumentos de avaliação e testes de triagem, para detecção de al guns distúrbios comuns nessa faixa etária, por causas fisiológicas, patológicas ou mesmo acidentais e violentas. No conjunto das unidades pesquisadas, 12 (63,2\%) têm essa vigilância em relação aos distúrbios de funcionalidade; dez (52,6\%) para a mobilidade; oito ( $42,1 \%$ ) para o isolamento social; sete $(36,8 \%)$ para os distúrbios nutricionais e depressão; quatro (21\%) para os problemas cognitivos; três (15,8\%) para os visuais; e apenas um (5,3\%) para os distúrbios de audição. É notável que nenhuma das três unidades de Curitiba realize abordagem preventiva para tais distúrbios nos idosos, o que é condizente com os resultados sobre os profissionais e recursos tecnológicos disponíveis nos serviços pesquisados.

A articulação intersetorial com as mais diversas áreas para atenção ao idoso é uma ação preconizada pela Política Nacional de Saúde da Pessoa I dosa e também por autores que discutem a atenção às pessoas em situação de violência ${ }^{19}$. Entre os serviços de reabilitação estudados, 13 $(68,4 \%)$ se integram com a área da ação social para atendimento ao idoso; dez $(52,6 \%)$ com as 
áreas da justiça e lazer; nove $(47,4 \%)$ com a área dos esportes; oito $(42,1 \%)$ com a da educação; e sete $(36,8 \%)$ com a da segurança. As áreas menos procuradas foram a de direitos humanos (seis unidades, 31,6\%), trabalho e turismo (cinco unidades, $26,3 \%$ ).

O relacionamento dos serviços com a rede de proteção social para os casos de idosos vítimas de violência parece não ser muito próximo, pois os gestores enfatizaram o escasso intercâmbio com outras instituições. Na opinião deum deles, a responsabilidade dessa interação é da Secretaria de Assistência Social, que tem programas específicos para essa comunicação. Outro considerou que essa relação é isolada, descontínua e baseada em ações pontuais, mostrando que real mente esse é um tema estranho à atuação da reabilitação.

Sobre o relacionamento com os serviços de proteção ao idoso, os técnicos afirmaram que pouco ou nada interferem quando 0 assunto é encaminhar uma pessoa em situação de violência para outras instituições. A conduta pareceser unânime: encaminham para o psicólogo e 0 assistente social.

0 idoso em tratamento de reabilitação muitas vezes carece de atendimento complementar pela idade avançada. Entretanto, a articulação com outros serviços para a atenção integral, interdisciplinar e intersetorial nem sempre é garantida. Entre os serviços de reabilitação estudados, $14(73,7 \%)$ encaminham pacientes para outras unidades de saúde; $13(68,4 \%)$ para hospitais gerais; 11 (57,9\%) para a Secretaria de Assistência/Ação Social; nove $(47,4 \%)$ para o Programa Saúde da Família/Programa Agentes Comunitários de Saúde(PSF/PACS); oito (42,1\%) para - Centro de Atenção Psicossocial (CAPS); sete (36,8\%) para hospitais psiquiátricos, M inistério Público econselhos dedireitos; seis (31,6\%) para organizações não governamentais (ONGs); e quatro (21\%) para delegacias.

Diversos autores têm discutido a relevância das informações do setor saúde e da qualidade desses registros. A informação é um direito dos cidadãos e ajuda na compreensão da magnitude dos acidentes eviolências. É essencial para osgestores dos serviços, fornece subsídios na tomada de decisões sobre as medidas de prevenção e de promoção da saúde ${ }^{23}$.

Poucas unidades se dedicam ao trabalho de notificar casos suspeitos ou confirmados de violência contra idosos que procuram os serviços de reabilitação: apenas três de $M$ anaus, uma do Rio deJ aneiro euma de Curitiba. Um serviço de Recife, um de Brasília e dois de Curitiba informaram que essa notificação depende do profissional.
O M inistério da Saúde criou uma ficha de notificação para ser usada em casos de suspeita ou confirmação de violência contra crianças e adolescentes, mulher e pessoa idosa. Alguns estados e municípios também já programaram uma ficha própria. Em Brasília e no Rio de Janeiro, nenhum serviço de reabilitação informou possuir ficha, fazer análises dos registros ou usar suas informações para planejar ações. A penas um serviço de M anaus, um de Recife e um de Curitiba usam ficha para notificação dos casos. Uma unidade de Recife e uma de Curitiba enviam os dados para o serviço de vigilância epidemiológica.

A notificação de casos suspeitos ou confirmados de violência contra idosos é uma questão prevista no Estatuto do Idoso em seu artigo 19. Dentre os poucos serviços que notificam o fazem, em sua maioria, para o M inistério Público: dois serviços de $M$ anaus e um dos demais municípios. No Rio de Janeiro, apesar de um serviço ter informado que faz a notificação, indicou que ela não segue para outra instituição.

Em Braślia e no Rio de Janeiro nenhuma unidade informou ter, em seu quadro, profissionais que receberam capacitação para identificar e atender os casos de violência e registrar sistematicamente as informações geradas pelo serviço. Duas unidades de M anaus e uma de Curitiba possuem técnico preparado para o devido registro. Já em Recife, os entrevistados afirmaram que contam com pessoas capacitadas para identificar e atender os casos de idosos vítimas de acidentes e violências. A avaliação qualitativa realizada pelos gestores de reabilitação mostra que, em geral, muitos têm dificuldades em falar sobre a atenção prestada a essa população no município onde atuam.

Após reflexão sobre a estrutura dos serviços eo atendimento prestado, osfisioterapeutas apresentaram uma visão positiva sugerindo ações potencialmente geradoras de prevenção das situações de violência. Relataram que, em geral, obtêm sucesso na reabilitação dos pacientes, ao proporcionar a retomada da locomoção, a orientação às famílias, o retorno à comunidade e a reintegração social. Outros destacaram a precariedade da aten ção prestada aos idosos, que contam com poucos profissionais que realizam atendimento específico (os poucos que trabalham na área só oferecem orientações): Acredito que quando há casos de violência contra idosos eles são mal atendidos (...). Converso com outros colegas que trabal ham em hospitais eeles falam sobreisso (Rio deJaneiro).

Outro ponto citado éo desarranjo social pela falta e pelo descumprimento de normas urba- 
nísticas saudáveis e seguras, que comprometem a mobilidade do idoso. São calçadas inapropriadas, travessias desafiadoras de vias públicas, obstáculos e ocupação irregular dos passeios. Também foram lembradas a questão da violência no trânsito, as inadequações e o desrespeito nos transportes e em outros locais públicos.

Os gestores sugeriram a necessi dade de facilitação da articulação com as áreas de proteção social. Para um deles, o idoso deveria chegar ao serviço com o diagnóstico de violência já documentado para possibilitar o feedback para as instituições que primeiro notificaram. Advogaram pelo fortalecimento das equipes multidisciplinares epela criação deum centro de referência para atender exclusivamente $o$ idoso e suas especificidades, assim como de um programa destinado ao cuidado de casos de acidentes eviolências contra esses usuários, com maior oferta de atenção qualificada.

0 trabalho de reabilitação preventiva deveria ser incentivado com discussões sobre estilos de vida saudáveis, cuidados com a saúde (alimentação, atividade física), participação na sociedade, entre outras ações. Foi apontada a importância de se incluírem nas agendas municipais discussões mais amplas sobre as questões específicas da população idosa, assim como de se facilitar a integração dos diversos setores como saúde, assistência social, educação e direitos humanos.

A escassez de profissionais para trabalhar na área da reabilitação do idoso foi citada como problema querequer pronto enfrentamento, seja com a contratação de técnicos especializados, seja com a qualificação dos que já estão atuando. Ressaltou-se a importância da divulgação, pela mídia e pelos serviços de reabilitação, de formas de prevenção de acidentes e violências mais comuns entre os idosos, como as quedas e os maus-tratos familiares, além dos serviços onde se buscar ajuda.

Finalmente, considerando-se o conjunto de indicadores formulados para 0 atendimento de reabilitação, pode-se notar que os serviços pesquisados em M anaus e Braślia estão mais bem preparados para atender os idosos vítimas de acidentes eviolência. No quese refereàsquestões mais específicas ao atendimento da pessoa ido- sa, como uso de protocolos de atendimento, atividades de reinserção na vida comunitária, promoção do autocuidado, fomento da rede de solidariedade para idosos frágeis e sua família e estímulo à participação em grupos, as unidades de Brasília sobressaem. Outras atividades como a abordagem preventiva de distúrbios, comuns nessa faixa etária, aparecem com maior frequência nos serviços do Rio de Janeiro.

Por sua vez, as unidades de reabilitação localizadas em Recife apresentam-se menos preparadas, especialmente no que tange aos itens de suporte laboratorial, capacitação de profissionais para identificar e atender os casos de idosos em situação de violência, registro e análise dos dados (Tabela 5).

\section{Considerações finais}

Ressalta-se que a implantação e a implementação das políticas que contemplam a redução da violência e a proteção ao idoso apresentam uma situação bastante desigual nos serviços de reabilitação das cidades pesquisadas.

0 atendimento de reabilitação mostra grandes fragilidades na implantação das políticas públicas aqui consideradas. Poucas unidades têm recursos para responder às especificidades deidosos vítimas de acidentes e violências, o que fica claro inclusive nas falas dos técnicos que não se consideram responsáveis pela escuta, pelo apoio, atendimento e orientação aos idosos com história de violência. Pelo contrário: fugindo totalmente à noção de atendimento interdisciplinar queé preconizada nessas situações, eles acreditam que devem apenas atuar sobre a lesão física e deixar queseus col egas de equipe, psicólogo eassistente social, respondam pela situação de violência.

Este estudo revela que a inserção do tema da violência no atendimento de reabilitação nessas cidades está muito aquém do desejável para os servi ços de saúde. Espera-se que, a partir da descrição aqui elaborada, gestores e profissionais de reabilitação possam encontrar subsídios para aprimorar suas ações, suas estruturas e suas metas de qualidade. 
Tabela 5. Resultado da aplicação dos indicadores aos serviços do atendimento de reabilitação.

\begin{tabular}{|c|c|c|c|c|c|}
\hline Indicador & M anaus & Recife & Brasília & $\begin{array}{c}\text { Rio de } \\
\text { Janeiro }\end{array}$ & Curitiba \\
\hline $\begin{array}{l}\text { Proporção de unidades que possuem mecanismos próprios ou } \\
\text { integração com a rede de serviços para suporte para laboratório de } \\
\text { radiologia e de patologia clínica. }\end{array}$ & 50,0 & 16,7 & - & - & - \\
\hline $\begin{array}{l}\text { Proporção de unidades que possuem protocolos para o } \\
\text { atendimento de reabilitação aos idosos vítimas de acidentes/ } \\
\text { violências. }\end{array}$ & 40,0 & 28,6 & 100,0 & - & 33,3 \\
\hline $\begin{array}{l}\text { Proporção de unidades de referência que realizam as principais } \\
\text { atividades propostas para seu nível de complexidade. }\end{array}$ & 100,0 & $(*)$ & - & 50,0 & 50,0 \\
\hline $\begin{array}{l}\text { Proporção de unidades que realizam atividades voltadas para } \\
\text { reinserção na vida comunitária, ações de promoção do } \\
\text { autocuidado, ações de fomento da rede de solidariedade para idosos } \\
\text { frágeis e sua família e ações de estímulo à participação dos idosos } \\
\text { em grupos de terceira idade, conselhos comunitários. }\end{array}$ & 80,0 & - & 100,0 & 50,0 & 66,7 \\
\hline $\begin{array}{l}\text { Proporção de unidades que possuem equipes multidisciplinares para } \\
\text { a reabilitação domiciliar dos idosos vítimas de acidentes e } \\
\text { violências. }\end{array}$ & 20,0 & - & - & - & - \\
\hline $\begin{array}{l}\text { Proporção de unidades que oferecem uma abordagem preventiva } \\
\text { com aplicação de instrumentos de avaliação e testes de triagem para } \\
\text { detecção de distúrbios cognitivos, visuais, mobilidade, audição, } \\
\text { depressão, comprometimento da funcionalidade, distúrbios } \\
\text { nutricionais e isolamento social. }\end{array}$ & 20,0 & 28,6 & 50,0 & 100,0 & - \\
\hline $\begin{array}{l}\text { Proporção de unidades cujos profissionais recebem capacitação para } \\
\text { identificação e atendimento dos casos de idosos vítimas de } \\
\text { acidentes e violência. }\end{array}$ & 40,0 & 14,3 & - & - & - \\
\hline $\begin{array}{l}\text { Índice de recursos humanos de unidades primárias para } \\
\text { atendimento ao idoso - Proporção de unidades primárias que } \\
\text { possuem equipe mínima de profissionais indispensáveis para seu } \\
\text { funcionamento; e que possuem profissionais com formação em } \\
\text { gerontologia/geriatria. }\end{array}$ & $(*)$ & 53,3 & 60,0 & $(*)$ & 80,0 \\
\hline $\begin{array}{l}\text { Îndice de recursos humanos de unidades intermediárias para } \\
\text { atendimento ao idoso - Proporção de unidades intermediárias que } \\
\text { possuem equipe mínima de profissionais indispensáveis para seu } \\
\text { funcionamento; e que possuem profissionais com formação em } \\
\text { gerontologia/geriatria. }\end{array}$ & 50,0 & 29,0 & $(*)$ & $(*)$ & $(*)$ \\
\hline $\begin{array}{l}\text { Índice de recursos humanos de unidades de referência para } \\
\text { atendimento ao idoso - Proporção de unidades de referência que } \\
\text { possuem equipe mínima de profissionais indispensáveis para seu } \\
\text { funcionamento; e que possuem profissionais com formação em } \\
\text { gerontologia/geriatria. }\end{array}$ & 33,3 & $(*)$ & 50,0 & 80,0 & 70,0 \\
\hline $\begin{array}{l}\text { Índice de integração da unidade/serviço com a rede - Proporção de } \\
\text { unidades que possuem integração com equipes do PSF visando à } \\
\text { manutenção da capacidade funcional do idoso; e recebem ou } \\
\text { encaminham pacientes do PSF/Pacs, CAPs, hospitais gerais, } \\
\text { psiquiátricos, unidades de saúde, M inistério Público, delegacias, } \\
\text { conselhos de direitos, Secretaria de Desenvolvimento/Assistência/ } \\
\text { Ação Social. }\end{array}$ & 40,0 & 53,0 & 35,0 & 70,0 & 90,0 \\
\hline $\begin{array}{l}\text { Índice de registro e análise dos dados - Proporção de unidades que } \\
\text { realizam o registro do atendimento aos acidentes/violências } \\
\text { classificados de acordo com a CID-10 e que fazem análise } \\
\text { sistemática deles. }\end{array}$ & 20,0 & 14,3 & - & - & - \\
\hline
\end{tabular}

(*) 0 município não possui essetipo deunidade. 


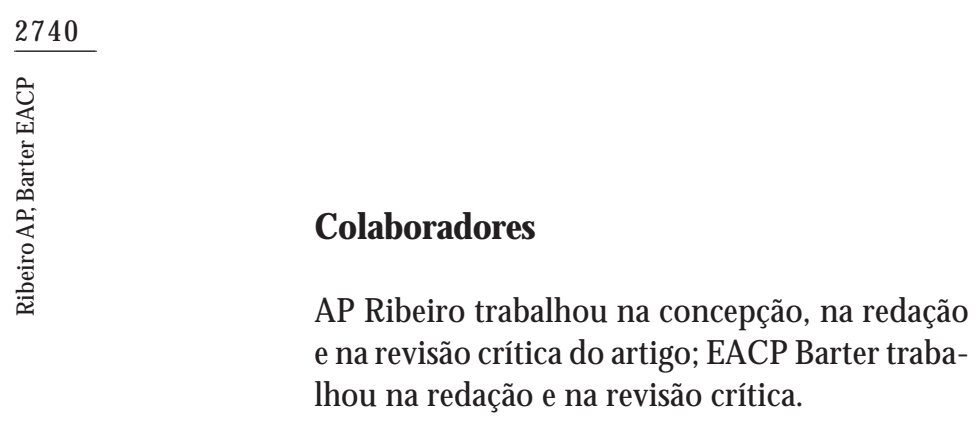

Referências

1. Gordilho A, Nascimento JS, Silvestre J, Ramos LR Freire M PA, Espindola N, Maia R, Veras R, Karsch $U$. Desafios a serem enfrentados no terceiro milênio pelo setor saúde na atenção integral ao idoso. Bahia Análise \& Dados 2001; 10(4):138-153.

2. Ramos LR. Fatores determinantes do envelhecimento saudável em idosos residentes em centro urbano: Projeto Epidoso, São Paulo. Cad Saude Publica 2003; 19(3):793-798.

3. Datasus (Departamento de Informática do SUS). [site da Internet] [acessado 2009 set]. Disponível em: http://tabnet.datasus.gov.br/cgi/tabcgi.exe?sih/ cnv/fruf.def

4. Brasil. Portaria MS/GM no 737, de 16 de maio de 2001: Política Nacional de Redução da Morbimortalidade por Acidentes e Violências. Diário Oficial da União 2001; 18 maio.

5. Perracini $M, N$ ajas $M$, Biltom $M$. Princípios em reabilitação gerontológica. In: Freitas EV, Py L, Neri AL, Cançado FAX, Gorzoni ML, Rocha SM, organizadores. Tratado de geriatria e gerontologia. Rio de Janeiro: Guanabara; 2002. p. 814-819.

6. Brasil. M inistério da Saúde. Política de Saúde do Idoso. Portaria no 1.395, de 9 de dezembro de 1999. Brasília: Ministério da Saúde; 1999.

7. Dacher JE. Rehabilitation and the geriatric patient. N urs Clin N orth 1989; 24(1):225-237.

8. Souza JAG, Iglesias ACRG. Trauma no idoso. Rev Assoc M ed Bras 2002; 48(1):79-86.

9. Minayo M CS, Assis SG, Souza ER. Avaliação por triangulação de métodos: abordagem de programas sociais. Rio de Janeiro: Editora Fiocruz; 2005.

10. Brasil. Estatuto do Idoso. Lei $n-10.741$, de 1 으 de outubro de 2003. Diário Oficial da U nião 2003; 3 out.

11. Brasil. Portaria no 2.528, de 18 de outubro de 2006: Política Nacional de Saúde da Pessoa Idosa. Diário Oficial da União 2006; 19 out.

12. Souza ER, Veiga JP. Ranking de mortalidade por homicídio, suicídio e acidente de transporte em municípios com mais de 100.000 habitantes [relatório de pesquisa]. Rio de Janeiro: Claves/Ensp/Fiocruz; 2004.

13. M inayo MCS, Deslandes SF, organizadoras. Análise diagnóstica da política nacional de redução da morbimortalidade por acidentes e violências. Rio de Janeiro: Editora Fiocruz; 2007.

14. Varela J. Los métodos de consenso en el sector sanitário. Gaceta Sanitária 1991; 5:114-116.
15. Jones J, Hunter S. Consensus methods for medical and health services research. British M ed Journal 1995; 331:153-168.

16. Bardin L. Análise de conteúdo. Lisboa: Edições 70; 1979.

17. M inayo MCS. O desafio do conhecimento. São Paulo: Hucitec; 2006.

18. Schraiber L B, D'Oliveira AFPL, Couto M T, Hanada $H$, Kiss LB, Durand JG, Puccia MI, Andrade, MC. Violência contra mulheres entre usuárias de serviços públicos de saúde da Grande São Paulo. Rev Saude Publica 2007; 41(3):359-367.

19. Souza ER, Ribeiro AP, Penna LMG, Ferreira AL, Santos NC, Tavares CM M . O tema viol \}encia intrafamiliar na concepção dos formadores dos profissonais de saúde. Cien Saude Colet 2009; 14(5):17091719.

20. Diogo MJE. O papel da enfermeira na reabilitação do idoso. Rev Lat Am Enferm 2000; 8(1):75-81.

21. Souza ER, Ribeiro AP, Atie S, Souza A. 0 estado de direito e a violência contra o idoso [relatório de pesquisa]. Rio de Janeiro: Claves/Ensp/Fiocruz; 2006.

22. M inayo MCS, Souza ER. Violência contra idoso: é possível prevenir. In: Brasil. Ministério da Saúde, Secretaria de Vigilância em Saúde. Impacto da violência na saúde dos brasileiros. Brasília: M inistério da Saúde; 2005. p. 141-169.

23. Njaine K. Qualidade da informação sobre morbimortalidade por causas externas. In: LIM CA, organizador. Gestão em saúde na prevenção e atenção às situações de violência. Rio de Janeiro: Fiocruz/Ensp/ EAD; 2007.

Artigo apresentado em 20/09/2009

Aprovado em 11/05/2010

Versão final apresentada em 27/07/2010 